\title{
Contrato de aquisição entre OGX e Petrobras para explorar petróleo
}

Conselho Administrativo de Defesa Econômica (Cade)

\section{MINISTÉRIO DA JUSTIÇA \\ CONSELHO ADMINISTRATIVO DE DEFESA ECONÔMICA — CADE Gabinete da Conselheira Ana Frazão}

\section{ATOS DE CONCENTRAÇÃO no 08700.005775/2013-19}

Requerente: OGX Petróleo e Gás e Petróleo Brasileiro S.A.

Advogados: Amadeu Ribeiro, Andreia Saad e outros.

Relatora: $\quad$ Conselheira Ana Frazão

\section{EMENTA}

Ato de Concentração. Operação realizada no Brasil. Procedimento sumário: outros casos (art. 8º, inc. VI Resolução CADE nº 2, de 29 de maio de 2012). Aquisição, por parte da OGX, de participação de $40 \%$ detida pela Petrobras em contrato de concessão para exploração, desenvolvimento e produção de óleo e gás no Bloco BS-4. Hipótese prevista no art. 88, incisos I e II, da Lei 12.529/2011. Conhecimento. Setores envolvidos: extração de petróleo e gás natural. Parecer da Superintendência-Geral pela aprovação da operação sem restrições quanto ao mérito, mas pela configuração da infração prevista no art. 88, § 3으, da Lei no 12.529/2011. Parecer da Procade pela configuração da mesma infração. Proposta de ACC. Aprovação da operação e homologação do ACC. 


\section{PALAVRAS-CHAVES}

Petróleo, acordo em controle de concentração, gun jumping.

\section{Voto}

\section{(Versão pública)}

\section{Requerentes}

1. A OGX Petróleo e Gás S.A. ("OGX") é uma sociedade anônima de capital fechado que integra o Grupo EBX e que atua na exploração, produção e comercialização de petróleo e gás natural.

2. A Petróleo Brasileiro S.A. - Petrobras ("Petrobras") é uma sociedade de economia mista que desenvolve, no âmbito nacional e internacional, atividades de exploração, produção, distribuição, refino, importação, comércio e transporte de petróleo, gás natural e seus derivados. A Petrobras também desenvolve diversas atividades ligadas à pesquisa, desenvolvimento e produção de várias formas de energia.

\section{Operação}

3. A operação consiste na aquisição, por parte da OGX, de participação de $40 \%$ detida pela Petrobras em contrato de concessão celebrado com a Agência Nacional de Petróleo para exploração, desenvolvimento e produção de óleo e gás no Bloco BS-4, localizado na bacia de Santos.

4. As participações no referido contrato são atualmente divididas da seguinte maneira:

a) Petrobras - 40\%;

b) Queiroz Galvão Exploração e Produção S.A. ("Queiroz Galvão") - 30\%;

c) Barra Energia do Brasil Petróleo e Gás Ltda. ("Barra Energia") - 30\%.

5. Após a realização da operação, a participação da Petrobras será transferida para a OGX, restando inalteradas as participações da Queiroz Galvão e da Barra Energia. 


\section{Taxa processual}

6. A taxa processual foi devidamente recolhida, como demonstra cópia autenticada do comprovante de recolhimento anexado às fls. 42 dos autos públicos.

\section{Dos pareceres da Procade e da Superintendência-Geral}

7. Após analisar, por solicitação da Superintendência-Geral, o presente feito, concluiu a ProCade que a operação em tela foi consumada antes de ser analisada pelo Cade.

8. Segundo a Procuradoria, diferentes elementos apontariam para a ocorrência no feito do chamado "gun jumping", isto é, da efetivação prematura do negócio avençado pelas partes sem a necessária autorização do Cade, em violação ao regime de notificação prévia estabelecida pela Lei 12.529/11.

9. Dentre tais elementos, poderiam ser citados a assunção imediata de direitos e obrigações pela Requerente no momento de assinatura do contrato, a efetiva participação da OGX nas decisões a serem tomadas pela Petrobras em relação ao objeto da operação antes mesmo da sua aprovação pelo Cade e o compartilhamento entre as partes de informações e decisões sobre questões concorrencialmente relevantes.

10. Dessa forma, entendeu a Procuradoria pela necessidade de aplicação, no presente caso, da multa prevista no artigo 88, § 3으, da Lei no 12.529/2011.

11. Em seu parecer, a Superintendência-Geral do Cade entendeu que a operação em tela se enquadraria na previsão do inciso II, artigo 90, da Lei 12.529/11 e deveria ser conhecida, em consonância com a jurisprudência recente deste Conselho em relação a operações envolvendo blocos para extração de petróleo.

12. Com relação ao mérito da operação, a Superintendência-Geral constatou a possível ocorrência de concentração horizontal decorrente de negócio, uma vez que a OGX desenvolve atividades que se sobrepõem àquelas afetadas pelo Contrato de Concessão do Bloco BS-4, quais sejam, exploração e produção de petróleo e gás natural no Brasil.

13. A Superintendência-Geral ressaltou, porém, que o Bloco BS-4 ainda não está em funcionamento, não tendo sido iniciada a produção de petróleo e de gás dos campos afetados pelo negócio em tela. 
14. Além do mais, notou a Superintendência-Geral que, mesmo que se considerasse a ocorrência de sobreposição horizontal entre o Bloco BS-4 e outros campos detidos pela $\mathbf{O G X}$, a operação em tela seria incapaz de gerar preocupações concorrenciais. Isso porque as participações do Grupo EBX nos segmentos de produção de petróleo e de gás no Brasil seriam bastante diminutas (respectivamente [CONFIDENCIAL] de acordo com os cálculos da Superintendência-Geral).

15. Pelo mesmo motivo, descartou a Superintendência-Geral quaisquer preocupações competitivas decorrentes da possível existência de integração vertical decorrente da operação.

16. Quanto à possível ocorrência da infração prevista no art. 88, § 3ํㅡ, da Lei no 12.529/2011, a Superintendência-Geral, depois de observar que inexiste no contrato avençado pelas partes cláusula suspensiva com relação à aprovação da operação por este Conselho, conclui, acolhendo o parecer da ProCade, que as Requerentes consumaram o negócio antes de obterem a necessária autorização do Cade.

17. Nesse sentido, encaminhou os autos ao Tribunal Administrativo para julgamento da questão e adoção das demais providências cabíveis.

\section{Do conhecimento}

18. No ano anterior à realização da operação, os faturamentos do Grupo Petrobras e do Grupo EBX foram, respectivamente, maiores que R\$ 750 milhões e R\$ 75 milhões no Brasil, razão pela qual conheço da operação.

\section{Do mérito}

\section{VI.1. Dos efeitos da operação}

19. Conforme bem exposto pela Superintendência-Geral, a operação em tela não levanta maiores preocupações concorrenciais.

20. Em primeiro lugar, tem-se que a parte adquirente, o Grupo EBX, detém participações bastante limitadas nos mercados de produção de petróleo e de gás no Brasil. Segundo os cálculos da Superintendência-Geral, tais participações sequer superam a marca de [CONFIDENCIAL] dos respectivos mercados. 
21. Além do mais, é de se notar que os campos do Bloco BS-4, objeto da operação, ainda não entraram em funcionamento. Nesse sentido, o negócio não gera efeitos imediatos sobre o mercado, sendo incerto o momento em que os campos afetados pela transação entrarão efetivamente em produção.

22. Além do mais, conforme já observado em outros julgamentos deste Conselho, o mercado afetado pela operação é caracterizado pela dominância de uma empresa: a Petrobras. Nesse sentido, a operação em tela poderia, inclusive, ser compreendida como um movimento de desconcentração, ainda que de dimensão muito restrita, uma vez que representa a alienação, por parte da Petrobras, de ativo que futuramente poderá passar a produzir petróleo e gás.

23. Nesse quando, não se vislumbram possíveis impactos anticompetitivos oriundos do negócio, seja pela do ponto de vista da concentração horizontal ou da perspectiva da integração vertical.

\section{VI.2. Da proposta de Acordo em Controle de Concentrações (ACC)}

24. Em 27/8/2013, a OGX apresentou proposta de Acordo em Controle de Concentrações (ACC), nos termos do artigo 125 do Regimento Interno do Cade. Referida proposta possui, em curta síntese, o seguinte teor:

a) a OGX reconhece a consumação prematura da operação e a configuração da infração prevista no artigo 88 § 3ํ da Lei n. 12.529/2011;

b) a OGX compromete-se a recolher ao Fundo de Defesa dos Direitos Difusos contribuição no valor de R\$3.000.000,00 (três milhões de reais), em razão da consumação prematura da operação e da configuração da infração estabelecida no artigo 88, § 3o, da Lei n. 12.529/2011;

c) referida contribuição será paga em dez parcelas mensais, devidamente atualizadas pela taxa Selic;

d) o atraso injustificado no recolhimento da contribuição estabelecida sujeita a OGX ao pagamento de multa diária no valor de $\mathrm{R} \$ 40.000,00$ (quarenta mil reais), além de implicar atualização do valor pela taxa Selic até a data do efetivo recolhimento.

25. Note-se que, diferentemente de outros ACCs firmados recentemente por este Conselho, a proposta da OGX não trata de nenhum remédio voltado a endereçar algum possível efeito anticompetitivo da operação, já que como se analisou anteriormente - inexistem no presente feito quaisquer 
preocupações concorrenciais relativas às alterações na estrutura de mercado decorrente do negócio em tela.

26. Nesse cenário, em que o negócio analisado não gera nenhum impacto anticompetitivo, a aprovação ou não do acordo proposto depende basicamente de considerações de política dissuasória em relação à prática da infração prevista no art. 88, § 3ํㅡㄹ da Lei no $12.529 / 2011$.

27. Em outras palavras, deve-se avaliar se a solução negociada representa, no caso concreto, uma forma de otimização do trabalho da Administração, com ganhos de tempo e de recursos na aplicação da legislação antitruste, e se não gera algum cenário de subpunição que beneficie o Requerente de forma indevida.

28. A partir de tal perspectiva, passo a analisar a conveniência e oportunidade do ACC proposto pela OGX.

\section{VI.3. Da análise de mérito do ACC}

29. Conforme já ressaltado pelo Cade em diferentes oportunidades, soluções negociadas em relação a práticas infrativas podem se mostrar convenientes e oportunas desde que (i) maximizem a efetividade da política antitruste dissuasória e (ii) não gerem um cenário de subpunição que favoreça os responsáveis pela infração.

30. Sobre o tema, são bastante interessantes as ponderações do ex-Conselheiro Paulo Furquim de Azevedo no julgamento do Requerimento no 08700.004992/2007-13, no qual se analisou a conveniência ou não de realização de TCC no âmbito de processo administrativo:

O objetivo da autoridade antitruste, por sua vez, é o enforcement da política de defesa da concorrência (...). Entende-se como enforcement da política de defesa da concorrência a sua capacidade de restringir e orientar comportamentos dos administrados, mais especificamente coibir condutas anticompetitivas e atos de concentração com potencial lesivo à concorrência e ao bem-estar social e do consumidor. Esta é a métrica que deve ser utilizada para se avaliar as condições de transação e o que se entende por "juízo e oportunidade" que deve seguir o Conselho em sua avaliação de propostas de TCC. Portanto, acordos entre representadas e administração devem ser feitos se e somente se 
ampliarem a dissuasão de práticas anticompetitivas, o princípio básico que orienta as atividades da agência de defesa da concorrência.

31. Embora tal raciocínio esteja tradicionalmente associado à análise de conveniência e oportunidade relativa à celebração de TCC no âmbito do controle de condutas, parece claro que ele também se aplica à situação deste feito, dada as particularidades da presente proposta de ACC.

32. Conforme exposto anteriormente, o ACC proposto pela OGX é diferente daqueles normalmente analisados pelo Cade, já que endereça não possíveis efeitos anticompetitivos no mercado decorrentes da operação, mas tão somente as consequências oriundas da infração relativa à consumação prematura do negócio.

33. O ACC proposto pela Requerente trata apenas da possível ocorrência da infração prevista no art. 88, § 3o, da Lei no $12.529 / 2011$, apontada tanto pela Superintendência-Geral quanto pela ProCade. Dessa forma, a análise da proposta da OGX não passa por nenhuma consideração acerca da estrutura do mercado afetado, mas apenas pela discussão referente à consumação prematura da operação e às suas consequências jurídicas.

34. Nesse sentido, resta evidente que o exame da proposta de ACC formulada pela OGX aproxima-se muito mais da análise de acordos em geral propostos no âmbito de processos administrativos do que daqueles realizados no âmbito de atos de concentração.

35. Diante da natureza puramente infrativa da questão endereçada pelo ACC proposto pela OGX, tem-se que os parâmetros básicos para a análise da presente proposta consistem (i) nas consequências jurídicas esperadas pela Requerente caso o acordo não seja realizado e a possível prática infrativa venha ser objeto de julgamento e (ii) nos ganhos proporcionados à política dissuasória antitruste pela celebração do acordo. Conforme já apontado diversas vezes por esse Conselho na análise de acordos relativos a condutas infrativas, o correto sopesamento e avaliação desses dois parâmetros podem trazer benefícios significativos à efetividade da legislação concorrencial. 


\section{Das consequências da conduta infrativa}

36. Em relação ao primeiro desses parâmetros, estabelece o art. 88, § 3o, da Lei $\mathrm{n}^{-}$12.529/2011, que os atos de notificação obrigatória não podem ser consumados antes de apreciados pelo Cade, sob pena de nulidade e de imposição de multa pecuniária. Referido artigo consagrou, no ordenamento jurídico brasileiro, o chamado controle prévio de estruturas, que condiciona a consumação de determinadas operações à obtenção, por parte das empresas envolvidas, de autorização ex ante dos órgãos de defesa da concorrência.

37. Vale notar que a previsão da pena de nulidade é essencial para o bom funcionamento do sistema de notificação prévia, no qual se procura garantir que as condições concorrenciais só sejam alteradas por um ato de concentração após a autoridade antitruste ter avaliado os seus possíveis impactos sobre os mercados afetados, conforme prevê o art. 88 , $4^{\mathrm{o}}$ da atual Lei Antitruste.

38. Assim, ao contrário do que ocorria na Lei no 8.884/94, que permitia que os atos de concentração fossem primeiramente consumados para apenas depois serem submetidos ao SBDC, o regime estabelecido pela Lei no 12.529 / 2011 veda por completo a consumação de um ato de concentração sem que antes as empresas envolvidas passem pelo processo administrativo de controle prévio de estruturas previsto no diploma concorrencial.

39. A única opção de uma operação ser consumada antes da decisão final do Cade no processo de controle prévio está disciplinada no art. $54, \S 1^{\mathrm{o}}$ da Lei 12.529/2011, que prevê a possibilidade de o Conselheiro-Relator autorizar, de forma precária e liminar, a realização do negócio, impondo condicionantes que preservem a reversibilidade da operação.

40. É justamente a impossibilidade de consumação das operações antes da aprovação do Cade que justifica o estabelecimento, na Lei 12.529/2011, de uma série de prazos próprios que devem ser cumpridos pela autoridade antitruste no controle de estruturas. Tal previsão busca impedir que a consumação das operações de notificação obrigatória fique sobrestada indefinidamente em decorrência de eventual demora na análise concorrencial.

41. Dessa forma, resta claro que todo regime de controle de concentrações desenhado pela 12.529/2011 tem como fundamento central a impossibilidade de as empresas realizarem qualquer ato capaz de alterar as condições de concorrência no mercado antes de o Cade ter concluído sua análise ou ter concedido a autorização liminar prevista no art. 54, § 1ㅇ da Lei Antitruste. 
42. A pena de nulidade prevista no art. 88, $\S 3^{\circ}$, da Lei $\mathrm{n}^{\circ} 12.529 / 2011$ representa, nesse contexto, corolário lógico do controle preventivo implementado a partir da entrada em vigor do novo diploma antitruste.

43. No presente caso, tanto a Superintendência-Geral quanto a ProCade apontaram a consumação prematura da operação realizada pelas Requerentes e ocorrência da infração prevista no art. 88, § 3으, da Lei no 12.529/2011. Além do mais, a própria Requerente reconhece, em sua proposta de ACC, que a operação em tela foi consumada antes de ser submetida à apreciação deste Conselho e que tal situação configura infração à Lei Antitruste.

44. Nesse cenário, surge a questão de qual o escopo de incidência da pena de nulidade estabelecida no art. 88, § 3으, da Lei no $12.529 / 2011$. Em outras palavras, quais são exatamente os atos negociais sob os quais incide a referida pena?

45. Referida questão se mostra extremamente relevante dado o altíssimo nível de complexidade das operações geralmente submetidas ao Cade, que se caracterizam pela celebração, por parte das empresas envolvidas, de uma infinidade de atos jurídicos tanto antes quanto depois da sua consumação.

46. Assim, embora uma interpretação literal do art. 88, § 3o, da Lei no 12.529/ 2011 leve a uma conclusão aparentemente simples, o aprofundamento do exercício hermenêutico em casos concretos parece revelar alguns limites à abrangência da referida norma. Com efeito, algumas situações jurídicas mostram-se de tal forma rotineiras e banais na vida empresarial contemporânea que é difícil imaginar que possam elas ser alcançadas pela pena de nulidade prevista no art. 88, $\S 3$ 을 da nova Lei Antitruste.

47. Exemplos claros nesse sentido podem ser encontrados na realização de atos como o pagamento a certos tipos de fornecedores (ex.: contas de luz e água), a aquisição de equipamentos de uso corriqueiro (ex.: materiais de escritório) e a contratação de serviços sem qualquer relevância concorrencial (ex.: manutenção predial).

48. Interpretação que inclua tais atos no âmbito da nulidade estabelecida no art. 88 da Lei no 12.529/2011 parece-me, pelo menos à primeira vista, desarrazoada, seja porque não traz nenhum benefício à efetividade da política antitruste, seja porque gera custos sociais gigantescos, a serem arcados principalmente por terceiros de boa-fé, que não estão de forma alguma relacionados à prática infrativa.

49. Por outro lado, parece claro que qualquer ato jurídico capaz de alterar, ainda que apenas potencialmente, as relações concorrenciais no mercado deve ser objeto da referida pena de nulidade. Aqui é importante rejeitar a 
tese de que seriam nulos apenas os atos que efetivamente gerassem efeitos negativos no mercado. Tal tese confunde os efeitos decorrentes da nulidade associada à consumação prematura da operação (art. 88, § 3o, da Lei nº 12.529/2011) com os efeitos da decisão de mérito do Cade que constatar a redução da concorrência oriunda de uma dada operação (art. 61 e art. 88, § 5o, da Lei no 12.529/2011). Como ressalvado anteriormente, a pena de nulidade é corolário lógico de um sistema de controle prévio de estruturas e, portanto, independe do julgamento de mérito do Cade num caso concreto.

50. O âmbito de incidência da pena de nulidade estabelecida no art. 88 , § 3 o , da Lei $\mathrm{n}^{\mathrm{o}}$ 12.529/2011 revela-se, assim, ao mesmo tempo questão de enorme relevância e de grande complexidade, já que não são de forma alguma óbvios, em uma interpretação razoável e proporcional da lei antitruste, os limites de aplicação da referida norma.

51. Apesar da relevância do tema para o desenvolvimento da política antitruste brasileira, tenho que, no presente feito, tal discussão se mostra secundária.

52. Isso porque, após oficiar a Requerente para que apresentasse todos os atos relacionados à consumação da operação e realizados após a sua implementação, tenho por clara a inexistência de qualquer ato que possa estar inserido no escopo de aplicação da pena de nulidade do art. 88, § 3o, da Lei Antitruste.

53. A lista de atos apresentada pelos Requerentes demonstra que todos os atos jurídicos realizados pelas empresas envolvidas na operação do Bloco BS-4 dizem respeito apenas a atos meramente operacionais, facilmente enquadráveis como atos de administração ordinária, consistindo basicamente na [CONFIDENCIAL].

54. De fato, observa-se que tais atos resumiram-se, basicamente, [CONFIDENCIAL].

55. Mais do que isso, os atos demonstram que a consumação do negócio ora em análise não [CONFIDENCIAL].

56. Tal situação fica bastante evidente [CONFIDENCIAL].

57. A participação da OGX restringiu-se basicamente [CONFIDENCIAL].

58. Desse modo, tenho que o âmbito de incidência da pena de nulidade, prevista no art. 88, § 3으, da Lei 12.529/2011, não tem como foco os atos praticados no bojo da presente operação. Tal conclusão é, ainda, reforçada pela peculiar situação regulatória existente no caso concreto, conforme descrito nos parágrafos 62 a 66 infra, que demonstra claramente que 
apenas recentemente a ANP passou a exigir, de forma expressa, a prévia aprovação do Cade para operações deste tipo.

59. Logo, em que pese a importância crucial da declaração de nulidade dos atos prematuramente consumados para o sistema de controle prévio, tenho que o caso concreto apresenta um conjunto de elementos que podem, em caráter excepcional, afastar a referida sanção indireta: (i) a operação não tem nenhum efeito anticoncorrencial, motivo pelo qual está sendo aprovada sem restrições, (ii) o bloco do qual a participação foi adquirida ainda não está em funcionamento, (iii) houve a prática apenas de atos operacionais ou de mera administração ordinária e (iv) foi constatada situação regulatória atípica, no seio da ANP, no que diz respeito à necessidade ou não da notificação obrigatória de operações desse tipo.

60. Somente a presença cumulativa de todos esses fatores permitiu que se afastasse, no caso, a declaração de nulidade dos atos prematuramente consumados.

61. Superada tal questão, tem-se que a segunda consequência jurídica estabelecida pelo art. 88, § 3ํㅡㄹ da Lei no 12.529/2011 diz respeito à imposição de multa pecuniária, de valor não inferior a $\mathrm{R} \$ 60.000,00$ (sessenta mil reais) nem superior a $\mathrm{R} \$ 60.000 .000,00$ (sessenta milhões de reais).

62. O regimento interno do Cade regulamenta o tema da seguinte forma:

Art. 112. O Cade poderá impor multa às partes que empreendam qualquer ação no sentido de consumação da operação de submissão

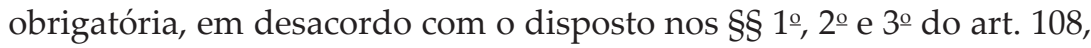
em valor não inferior a $\mathrm{R} \$ 60.000,00$ (sessenta mil reais) e não superior a $\mathrm{R} \$ 60.000 .000,00$ (sessenta milhões de reais), nos termos do art. 88, § 3으, da Lei no 12.529 , de 2011.

$\S 1$ № cálculo da multa, o Cade levará em conta o porte das requerentes, o dolo, a má-fé e a potencialidade anticompetitiva da operação, dentre outros fatores que considerar relevantes.

$\S 2^{\circ}$ A multa prevista no caput será imposta sem prejuízo da declaração de nulidade de atos já praticados e de apuração de eventual conduta anticompetitiva, nos termos do art. 69 da Lei no 12.529, de 2011.

$\S 3^{\circ}$ A instauração de procedimento administrativo para apuração de ato de concentração econômica e sua conversão em processo administrativo para análise de ato de concentração econômica não afastam a hipótese de imposição de multa prevista no caput. 
63. O art. 45 da Lei 12.529/2011, por sua vez, estabelece os seguintes parâmetros para a aplicação das penas pelo Cade:

Art. 45. Na aplicação das penas estabelecidas nesta Lei, levar-se-á em consideração:

I - a gravidade da infração;

II - a boa-fé do infrator;

III - a vantagem auferida ou pretendida pelo infrator;

IV - a consumação ou não da infração;

V - o grau de lesão, ou perigo de lesão, à livre concorrência, à economia nacional, aos consumidores, ou a terceiros;

VI - os efeitos econômicos negativos produzidos no mercado;

VII - a situação econômica do infrator; e

VIII - a reincidência.

64. Com relação ao inciso I do art. 45 da Lei Antitruste, tenho que a infração de gun jumping é sempre de uma gravidade elevada, mesmo nos casos em que as operações consumadas precocemente não levantem preocupações concorrenciais, uma vez que tal prática representa desafio frontal ao próprio regime de controle prévio de estruturas estabelecido pela Lei $\mathrm{n}^{\mathrm{o}}$ 12.529/2011.

65. No que se refere à questão da má-fé, do dolo e da vantagem pretendida pelo infrator, o presente caso guarda algumas particularidades que devem ser observadas. Isso porque a notificação do ato deu-se em meio a mudanças nos procedimentos adotados pela ANP para análise de cessões de direitos e obrigações dos contratos de concessão de petróleo.

66. Tais mudanças foram implementadas a partir do Ofício Circular n. 003/2013/SEP, editado pelo Superintendente de Exploração da ANP em $4 / 4 / 2013$, por meio do qual se informou aos agentes de mercado que a análise por parte de ANP de pedidos de autorização para as referidas cessões só seria realizada depois que os interessados apresentassem decisão do Cade aprovando a operação.

67. Antes da edição do Ofício Circular n. 003/2013/SEP, a ANP não exigia das empresas envolvidas em contratos de cessão a apresentação da autorização prévia deste Conselho para que fosse concedido o aval regulatório necessário para a implementação da operação, conforme se extrai do guia de procedimentos para cessão de direitos e obrigações dos contratos 
de concessão nas fases de exploração, desenvolvimento e produção de petróleo e gás natural editado pela ANP em 2012 (fl. 542).

68. Por outro lado, a versão atual do referido guia (fl. 548), atualizada no presente ano após a edição do Ofício Circular n. 003/2013/SEP, prevê expressamente a necessidade da aprovação prévia do Cade para que um pedido de autorização para cessão de direitos seja apreciado pela Diretoria da ANP, nos seguintes termos:

Os pedidos de autorização para Cessão de Direitos e Obrigações serão devolvidos se não forem apresentados rigorosamente de acordo com este Procedimento, contendo os seguintes documentos:

(...)

k) Parecer Técnico, emitido pelo Cade, de aprovação da aquisição de ativos relativos aos Contratos de Concessão para Exploração, Desenvolvimento e Produção de Petróleo e Gás Natural, em cumprimento do art. 88 da Lei no 12.529/2011 (considerando-se os valores previstos na Portaria Interministerial MJ/MF no 994, de 30 de maio de 2012); ou Declaração de Faturamento Bruto Anual ou Volume de Negócios no País, assinada pelo(s) Cedente(s) e Cessionário(s), onde deverá constar que Cedente(s) e Cessionário(s) não se enquadram nas hipóteses previstas no art. 88 da Lei no $12.529 / 201$.

Obs.: O pedido de Cessão poderá vir, inicialmente, acompanhado do comprovante de protocolo de submissão da operação ao Cade.Oprocesso de Cessão, entretanto, só será levado à análise da Procuradoria-Geral Federal e à deliberação da Diretoria Colegiada mediante apresentação do documento emitido pelo Cade, de aprovação da aquisição do ativo objeto da Cessão de Direitos e Obrigações.

69. Nota-se, assim, alteração no contexto regulatório que, embora não exima a Requerente da sua obrigação legal estabelecida pelo diploma antitruste, aponta para a inexistência de má-fé ou de busca por uma vantagem indevida no presente caso. Em verdade, o baixo número de operações desse gênero (cessões nos contratos de concessão de exploração, desenvolvimento e produção de petróleo e gás natural) que foram submetidas ao Cade desde a entrada em vigor da Lei n. 12.529/2011 parece indicar que a praxe do mercado até a edição do Ofício Circular n. 003/2013/SEP era realizar tais operações sem submetê-las ao controle antitruste de estruturas. Assim, é 
possível que haja outros negócios semelhantes realizados na indústria de petróleo brasileiro que não tenham sido notificados ao SBDC, o que exige a instauração de procedimento administrativo para apuração de ato de concentração econômica, nos termos do artigo 48, VI da Lei n. 12.529/2011.

70. Em relação ao critério do porte econômico previsto no art. 112, $\S 1^{\circ}$ do Regimento Interno, tem-se que o faturamento da OGX no Brasil foi de R\$ 296 milhões enquanto o da Petrobras foi de $\mathrm{R} \$ 276$ bilhões.

71. Quanto ao critério estabelecido pelo inciso IV artigo 45, a consumação da infração é certa, tanto que foi reconhecida pela própria Requerente.

72. Já em relação aos incisos V e VI do referido artigo, tem-se que o ato de concentração em tela não levantou, como já analisado, nenhuma preocupação concorrencial mais séria, tanto que recebeu tratamento sumário da Superintendência-Geral. Além do mais, a operação não gerou até o momento nenhum efeito sobre o mercado relevante afetado, já que o bloco objeto da operação ainda não entrou em funcionamento. Assim, não há que se falar em efeitos econômicos negativos produzidos no mercado nem em lesão à livre concorrência, aos consumidores ou a terceiros.

73. No que toca à situação econômica do infrator (art. 45, inciso VII), documentos juntados pela Requerente demonstram a difícil posição financeira em que se encontra a $\mathbf{O G X} .{ }^{1} \mathrm{O}$ fluxo de caixa consolidado da empresa no ano de 2013 comprova um agravamento progressivo da sua situação econômica (fl. 529):

$\begin{array}{cc}\text { Mês } & \text { Saldo Final Livre } \\ \text { Jan-13 } & \text { [CONFIDENCIAL] } \\ \text { Fev-13 } & \text { [CONFIDENCIAL] } \\ \text { Mar-13 } & \text { [CONFIDENCIAL] } \\ \text { Abr-13 } & \text { [CONFIDENCIAL] } \\ \text { Mai-13 } & \text { [CONFIDENCIAL] } \\ \text { Jun-13 } & \text { [CONFIDENCIAL] } \\ \text { Jul-13 } & \text { [CONFIDENCIAL] }\end{array}$

1 (i) "Produção de petróleo da OGX, de Eike, cai 78,31\% em abril", Folha de S.Paulo, 7/5/13, disponível em: <www1.folha.uol.com.br/mercado/2013/05/1274540-producao-de-petroleoda-ogx-de-eike-cai-7831-em-abril.shtml>; (ii) "Dívida faz OGX contratar consultoria da Blackstone, diz agência. A petrolifera acabou se tornando uma grande decepção para os investidores, pois a produção ficou abaixo do que era esperado", Veja, 14/8/13, disponível em: <http://veja.abril.com. $\mathrm{br} /$ noticia/economia/divida-faz-ogx-contratar-consultoria-da-blackstone-diz-agencia> e (iii) "OGX lidera endividamento em dólar do grupo EBX, de Eike", Época, 13/6/13, disponível em: $<$ http://epocanegocios.globo.com/Informacao/Dilemas/noticia/2013/06/ogx-lidera-endivida mento-em-dolar-do-grupo-ebx-.html>. 


$\begin{array}{cc}\text { Ago-13 } & \text { [CONFIDENCIAL] } \\ \text { Set-13 } & \text { [CONFIDENCIAL] } \\ \text { Out-13 } & \text { [CONFIDENCIAL] } \\ \text { Nov-13 } & \text { [CONFIDENCIAL] } \\ \text { Dez-13 } & \text { [CONFIDENCIAL] }\end{array}$

74. Tais informações confirmam as notícias veiculadas pela imprensa especializada, que relatam de forma recorrente a difícil situação vivida pela OGX1 e pelas demais empresas que integram o seu grupo econômico EBX.

75. Por fim, quanto ao critério do inciso VIII do artigo 45, não se constata a ocorrência de reincidência no feito em tela.

76. Em sua proposta de ACC, a OGX comprometeu-se a recolher ao Fundo de Direitos Difusos o valor de R\$3.000.000,00 (três milhões de reais) em razão da configuração da referida infração. A questão que se coloca, portanto, é se o valor proposto é suficiente para, considerados os aspectos de dosimetria acima relatados, proporcionar ganhos de efetividade ao sistema de controle antitruste sem comprometer a sua capacidade dissuasória.

77. A adequada resposta a tal questão passa pela avaliação dos benefícios oriundos da adoção da via negocial no presente caso, coisa que passo a fazer a seguir.

\section{Dos benefícios oriundos da celebração de acordo}

78. Da forma como proposto, o ACC formulado pela OGX otimiza a implementação da legislação concorrencial em pelo menos dois aspectos.

79. Primeiramente, com relação ao caso concreto, a celebração do acordo significa a aceleração da atuação dissuasória do Cade em alguns anos. Isso porque a celebração do acordo fará com que OGX seja responsabilizada de forma muito mais rápida pelos seus atos do que ocorreria caso a empresa fosse condenada e recorresse ao Judiciário.

80. Embora a judicialização das decisões condenatórias do Cade não seja em si mesma um problema, até mesmo pelo seu altíssimo nível de preservação nas várias esferas do Judiciário, é inegável que a resposta final da máquina judicial brasileira às questões que lhe são submetidas tende a ser demorada. Nesse contexto, a adoção de soluções negociadas pode representar um mecanismo célere de enfrentamento de determinadas 
questões, permitindo que a autoridade antitruste intervenha no mercado com uma efetividade que não seria possível pela rota tradicional do processo adversarial.

81. Em segundo lugar, a celebração do acordo traz benefícios dinâmicos ao sistema de controle de estruturas que superam os limites do caso concreto.

82. Na proposta apresentada, a OGX reconhece que a operação em tela foi consumada antes de ser submetida à apreciação deste Conselho e que tal situação configura infração à Lei Antitruste, restando superada qualquer discussão acerca da necessidade ou não de submissão do presente ato bem como de operações congêneres - ao Sistema Brasileiro de Defesa da Concorrência.

83. Cria-se, assim, um importante precedente no controle de estruturas da indústria petrolífera brasileira, que - conforme relatado acima - parece ter adotado como praxe, até a edição do Ofício Circular n. 003/2013/SEP, realizar operações de cessão de direitos e obrigações em contratos de concessão de petróleo sem submetê-las antes à apreciação do Cade.

84. Nesse contexto, parece claro que o reconhecimento da infração pela OGX representa um elemento relevante a ser considerado na avaliação de conveniência e oportunidade de celebração do acordo.

\section{Da conveniência e oportunidade da celebração do ACC}

85. No exame de propostas de acordo como esta formulada pela OGX, em que agentes investigados pelo possível cometimento de uma conduta infrativa buscam criar uma solução negociada que seja conveniente para a autoridade antitruste, deve o Cade avaliar se a via negocial gera ou não mais benefícios do ponto de vista da implementação da legislação concorrencial do que a rota adversarial tradicional.

86. No presente feito, a questão que se apresenta é se o ACC formulado pela OGX constitui ou não uma forma mais efetiva de enforcement das previsões sancionatórias do art. 88, § 3oㅡㄹ da Lei no ${ }^{-12.529 / 2011}$ do que o prosseguimento natural do julgamento do ato de concentração.

87. Dado que, conforme já apontado anteriormente, não se cogita da incidência da pena de nulidade no caso concreto, resta saber se o valor da contribuição estabelecida na proposta de ACC é conveniente e oportuno frente (i) à multa esperada pela Requerente caso o processo seguisse o seu curso natural e (ii) aos benefícios proporcionados pela celebração do acordo. 
88. Diante das especificidades do caso concreto, tenho que a resposta a tal questão é afirmativa.

89. Embora inexista hoje jurisprudência do Cade que balize os parâmetros para multa em casos de gun jumping, o valor proposto encontra-se na mesma faixa de multas aplicadas recentemente pelo Conselho em outras espécies de infrações processuais.

90. Veja-se, por exemplo, que no Auto de Infração n. 08700.010047/2012-48, ${ }^{2}$ no qual ficou constatada (i) a ocorrência de infração de alta gravidade (falseamento de informação crucial para a análise antitruste), (ii) a ausência de boa-fé por parte das autuadas, (iii) fortes vantagens em favor dos infratores decorrentes da prática apenada, (iv) a existência de riscos de lesão à concorrência e de potenciais efeitos econômicos negativos, a multa aplicada pelo Cade foi de $\mathrm{R} \$ 3.500 .000,00$ (três milhões e quinhentos mil reais).

91. Assim, considerando as particularidades do presente caso que devem se fazer sentir na dosimetria da pena, em particular (i) a ausência de má-fé ou de busca por uma vantagem indevida por parte da Requerente, (ii) a inexistência de efeitos econômicos negativos produzidos no mercado ou de lesão à livre concorrência, aos consumidores ou a terceiros e (iii) a delicada situação econômica da OGX, o valor da contribuição proposta revela-se suficiente para garantir a capacidade dissuasória do sistema de controle antitruste.

92. Além do mais, os benefícios oriundos da adoção de uma solução consensual são relevantes, não quedando restritos ao enfrentamento do caso concreto, mas também gerando importante precedente para a análise de atos de concentração por parte do Cade no âmbito da indústria petrolífera.

\section{Conclusão}

93. Ante o exposto, conheço da operação e, acolhendo no que couber o parecer da Superintendência-Geral, aprovo-a, quanto a seu mérito, sem restrições.

2 Auto de Infração $n^{\underline{o}}$ 08700.010047/2012-48, referente ao Ato de Concentração $\mathrm{n}^{0}$ 8700.004155/2012-81. Autuadas: Azul S.A. e Trip Linhas Aéreas S.A. Conselheiro-Relator Ricardo Machado Ruiz. 
94. Voto também pela homologação do Acordo em Ato de Concentração proposto pela OGX, que trata da infração prevista no artigo 88 § $3^{\circ}$ da Lei $12.529 / 2011$.

95. Por fim, recomendo à Superintendência-Geral a abertura de procedimento para apuração de atos de concentrações relativos a cessões de direitos e obrigações em contratos de concessão ocorridos na indústria petrolífera desde a entrada em vigor da Lei n. 12.529/2011.

É o voto.

Brasília, 28 de agosto de 2013.

Ana Frazão

Conselheira-Relatora 